\title{
Seizure as the Cause of Atrial Fibrillation
}

\author{
Mehdi Momeni (D), Amirhosein Jahanshir (D) \\ Department of Emergency Medicine, Tehran University of Medical Sciences, Tehran, Iran
}

Cite this article as: Momeni M, Jahanshir A. Seizure as the Cause of Atrial Fibrillation. J Emerg Med Case Rep 2018; 9(4): 75-6.

\begin{abstract}
Introduction: Cardiac dysrhythmias are commonly seen with seizures, and atrial fibrillation (AF) is one of the rarest peri-ictal dysrhythmias.

Case Report: Here we present a case of AF that starts and ends with seizure episodes in a 72-year-old man.

Conclusion: The pathophysiology of such dysrhythmias is not completely understood, but autonomic system activation during seizures has been proposed to be the cause. Some believe that AF is the effect and not the cause of seizure. To the best of our knowledge, this case is the most complete evidence of causality of seizure for AF.

Keywords: Seizure, atrial fibrillation, dysrhythmia
\end{abstract}

Received: 23.11.2017 Accepted: 15.03.2018

\section{Introduction}

Cardiac dysrhythmias are commonly seen with seizures, especially generalized tonic-clonic seizures (GTCS). Sinus tachycardia is the most frequently encountered dysrhythmia (87\%), and asystole, ventricular tachydysrhythmia, and sinus bradycardia, which are the most lethal ictal dysrhythmias, occur in less than 5\%-10\% of cases (1). Peri-ictal atrial fibrillation (AF) is very rare, and here we present a case of AF that starts and ends with seizure episodes.

\section{Case Report}

The authors have obtained the informed consent of the patient for publishing this case.

A 72-year-old man was brought to our emergency department (ED) with the complaint of seizure. His wife reported that he was standing when suddenly lost his consciousness and fell down. His eyes were wide open and fixed in an upward gaze. After a few seconds, his limbs started to jerk, which lasted less than 1 min; then, he lost bladder control. He regained complete consciousness after $5 \mathrm{~min}$. According to the emergency medical technicians, his vital signs and bedside glucose test results were normal, and he had no postictal deficits. They transported him to our ED considering it to be an episode of GTCS.

The patient was hemodynamically stable and alert in ED, but he could not remember the event. His heart rate was 80 regular beats per minute (bpm) and pulse was regular. We could not find any past history of neurological or cardiovascular diseases; furthermore, the patient had no history of drug or alcohol abuse and was not taking any medication.

While we were preparing him for recording an electrocardiogram (ECG), he suddenly lost his consciousness and started to convulse again. His carotid pulse was well palpable and, obviously, irregular. This episode lasted for about 1 min, and after 5 min, he became conscious without any neurological deficit. His blood pressure was 150/80 mm Hg and pulse was regular at 90 bpm. We performed a 12-lead ECG; his cardiac rhythm was normal sinus rhythm (NSR). Brain computed tomography images 
showed normal findings, and we put him on continuous lead-II ECG monitoring and requested neurology and cardiology consultations.

Thirty minutes later, he had another seizure episode. After $10 \mathrm{~s}$, we noted that his NSR changed to AF with rapid ventricular response (about $120 \mathrm{bpm}$ ), which persisted throughout and $10 \mathrm{~s}$ after the seizure and then spontaneously converted back to NSR. The pattern of convulsions was compatible with GTCS, and we gave him a loading dose of phenytoin. He had another episode of seizure after about 1 h; his cardiac rhythm changed from NSR to AF with rapid ventricular response (about $130 \mathrm{bpm}$ ) and then changed back to NSR. Although we wanted to admit him into the hospital for more detailed evaluation, he left the hospital against medical advice after remaining seizure free for $3 \mathrm{~h}$. We referred him to our outpatient neurology clinic, but he did not visit again.

\section{Discussion}

Brief AF is a rare postictal dysrhythmia (1), but in case of AF and loss of consciousness, it is important to consider seizure as the cause of AF (2). The first case report on the relation of AF and seizure was published in 1970 (3). Recently, in a systematic review, Van der Lende et al. reported on 13 patients experiencing postictal AF since 1970 (4). Among them, in three patients who had video EEG proof of their epileptic events, AF lasted for 10, 55, and $>110 \mathrm{~s}$. But in the remaining 10 patients who had no EEG proof, the duration of AF was 1.5-25 h.

The pathophysiology of peri-ictal dysrhythmias is not completely understood. Some authors believe that cardiac dysrhythmias are related to the type and duration of seizure episodes (5). Simon and Britton believe that seizures increases the risk of peri-ictal dysrhythmias by altering the autonomic function $(6,7)$; however, there are other authors who consider dysrhythmias as the cause (not the effect) of seizure (6).

Despite incomplete pathophysiological information on this topic, autonomic function is thought to be the most important factor in the pathophysiology of peri-ictal dysrhythmias $(5,7)$. Generalized seizures with longer duration may strongly stimulate the autonomic system and increase the risk for dysrhythmias (6). Because peri-ictal sinus tachycardia is more frequent than sinus bradycardia, we can assume that sympathovagal balance is more likely to shift toward a relative activation of sympathetic system during seizure episodes (8). On the other hand, asystole, bradycardia, and AF, which occur rarely during seizure episodes, may occur due to a relative activation of parasympathetic system.

To establish a cause and effect relation between the two events, we at least need to show a temporal relation between them. Previous case reports could find an association between the onset of seizure and AF, but not between their terminations. Our presented case was of a new-onset seizure, although we could not prove it using EEG. In this case, we found a direct and temporal relation of both the onset and termination of seizure with $A F$, which reoccurred several times, Although seizure is not the sufficient cause of AF, the temporal order of events in this case report is in favor of seizure as the cause of AF and not vice versa. To the best of our knowledge, this is the most complete evidence of causality of seizure for AF.

\section{Conclusion}

Although we do not know the pathophysiological relationship between the two, seizure can be a cause of AF. In the present case, in which multiple seizure episodes were observed, we could show a temporal relation between seizure and AF.

Informed Consent: Verbal informed consent was obtained from the patient who participated in this study.

Peer-review: Externally peer-reviewed.

Author Contributions: Concept - A.J;; Design - A.J.; Supervision - A.J.; Materials - A.J., M.M.; Data Collection and/or Processing - A.J., M.M.; Analysis and/ or Interpretation - A.J., M.M.; Literature Search - A.J., M.M.; Writing Manuscript - A.J.; Critical Review - M.M.

Conflict of Interest: The authors have no conflict of interest to declare.

Financial Disclosure: The authors declared that this study has received no financial support.

\section{References}

1. Vedovello M, Baldacci F, Nuti A, Cipriani G, Ulivi M, Vergallo A, et al. Periictal prolonged atrial fibrillation after generalized seizures: description of a case and etiopathological considerations. Epilepsy Behav 2012; 23: 377-8. [CrossRef]

2. Herskovitz M, Schiller Y. Atrial fibrillation associated with epileptic seizures. Arch Neurol 2012; 69: 1197-9. [CrossRef]

3. Mathew NT, Taori GM, Mathai KV, Chandy J. Atrial fibrillation associated with seizure in a case of frontal meningioma. Neurology 1970; 20: 7258. [CrossRef]

4. van der Lende M, Surges R, Sander JW, Thijs RD. Cardiac arrhythmias during or after epileptic seizures. J Neurol Neurosurg Psychiatry 2016; 87: 69-74.

5. Nei M, Ho RT, Abou-Khalil BW, Drislane FW, Liporace J, Romeo A, et al. EEG and ECG in sudden unexplained death in epilepsy. Epilepsia 2004; 45: 338-45. [CrossRef]

6. Simon RP, Aminoff MJ, Benowitz NL. Changes in plasma catecholamines after tonic-clonic seizures. Neurology 1984; 34: 255-7. [CrossRef]

7. Britton JW, Ghearing GR, Benarroch EE, Cascino GD. The ictal bradycardia syndrome: localization and lateralization. Epilepsia 2006; 47: 737-44. [CrossRef]

8. Park HW, Shen MJ, Lin SF, Fishbein MC, Chen LS, Chen PS. Neural mechanisms of atrial fibrillation. Curr Opin Cardiol 2012; 27: 24-8. [CrossRef] 